\title{
ИССЛЕДОВАНИЕ КОРРЕЛЯЦИИ МАСТИТА И ЭНДОМЕТРИТА У ПЛОТОЯДНЫХ
}

\author{
V.V. Chekrysheva, A.K. Garkusha
}

\section{THE STUDY OF CORRELATION OF MASTITIS AND ENDOMETRITIS IN CARNIVORS}

Чекрышева В.В. - канд. ветеринар. наук, доц. каф. акушерства, хирургии и фризиологии домашних животных Донского государственного аграрного университета, Ростовская обл., Октябрьский р-н, пос. Персиановский.

E-mail: veterinar1987@mail.ru

Гаркуша А.К. - ветеринарный врач ветеринарной клиники «Черная кошка, белый кот», Ростовская обл., г. Азов.

E-mail: mir.veterinarii@yandex.ru

Представленная к изучению проблема актуальна в первую очередь для владельцев животных и специалистов, занимающихся разведением отдельных пород животных. Содержание домашних животных в условиях городских квартир, влияние стрессовых и экологических фракторов, полная зависимость режима содержания собак от образа жизни владельца и от того, насколько ответственно владелец относится к своему животному, отражаются на состоянии животного. В ходе проведенных исследований наблюдениям подверглись 40 собак различных возрастов и пород. Исследования проводились в условиях ветеринарной клиники города Азова Ростовской области. В результате проведения исследований установлена корреляция заболеваемости маститом и эндометритом с возрастом у сук. Животные в возрасте от 6 до 10 лет болеют наиболее часто. При анализе распространенности заболеваний в зависимости от породы собак пришли к выводу, что существенной породной предрасположенности к этим заболеваниям не выявлено. Однако чаще с патологией половой системы регистрировались беспородные животные. При мастите молочная железа увеличена в размере, горячая на ощупь, гиперемирована, болезненна, из сосков с трудом выделяется секрет серо-желтого ивета. Общая температура тела у собак находится
Chekrysheva V.V. - Cand. Veterinary Sci., Assoc. Prof., Chair of Obstetrics, Surgery and Physiology of Pets, Don State Agrarian University, Rostov Region, Oktyabrsky District, S. Persianovsky.

E-mail: veterinar1987@mail.ru

Garkusha A.K. - Veterinary Surgeon, Veterinary Clinic "Black Cat, White Cat", Rostov Region, Azov. E-mail: mir.veterinarii@yandex.ru

на верхних границах нормы либо превышает ее незначительно. Также одним из симптомов является полидипсия. При эндометрите у сук общее состояние животного угнетено, температура тела повышена, отмечается одышка, полидипсия, снижение аппетита или полный отказ от корма. При пальпации брюшная стенка напряжена, болезненная, тело и рога матки увеличены. При вагинальном исследовании слизистая оболочка преддверия и влагалища гиперемирована, отечная, влажная; влагалищная часть шейки матки увеличена, цервикальный канал приоткрыт, отмечается выделение экссудата бело-желтого ивета с неприятным запахом. При анализе заболеваемости собак маститом и эндометритом была установлена взаимосвязь. При ультразвуковом сканировании матка визуализируется хорошо, стенки утолщены, эхогенность снижена, эндометрий утолщен, небольшое количество анэхогенного содержимого. При ультразвуковом сканировании воспаленной молочной железы отмечается снижение эхогенности тканей.

Ключевые слова: мастит, эндометрит, молочная железа, половая система, воспалительньй процесс, собаки, суки, самки, воспаление молочной железы, воспаление половой системы самки, воспаление эндометрия. 
The problem presented to studying is actual first of all for the owners of the animals and experts engaged in cultivation of separate breeds of animals. Pets keeping in the conditions of city apartments, the influence of stressful and ecological factors, complete dependence of detention regime of dogs from the way of life of the owner and from that, how the owner is responsible concerning to the animal, are reflected in the condition of an animal. During conducted researches 40 dogs of various age and breeds underwent supervision. The researches were conducted in the conditions of veterinary clinic of the city of Azov of Rostov Region. As a result of carrying out the researches the correlation of incidence of mastitis and endometritis in a bough was established with age. The animals aged from 6 to 10 years were ill most often. In the analysis of the prevalence of the diseases depending on a dog breed came to the conclusion that essential pedigree predisposition to these diseases was not revealed. However, more often with the pathology of reproductive system not purebred animals were registered. At mastitis the mammary gland is increased in a size, hot to the touch, hyperemic, painful, from nipples the secret of gray-yellow color is hardly allocated. General body temperature in the dogs is on the upper bounds of the norm or it exceeds slightly. Also one of the symptoms is polydipsia. At endometritis in a bough general condition of the animal is oppressed, body temperature is increased, short wind, a polydipsia, loss of appetite or full refusal of the forage is noted. At the palpation the belly wall is strained, painful, the body and horns of uterus are enlarged. At vaginal research the mucous membrane of the threshold and the vagina is hyperemic, edematous, damp; vaginal part of uterus neck is increased, cervical channel is slightly opened, the release of exudate of whiteyellow color with an unpleasant smell is noted. In the analysis of the incidence of mastitis and endometritis in dogs the interrelation was established. At ultrasonic scanning the uterus is visualized well, the walls are thickened, the echogenicity is lowered, endometrium is thickened, a small amount of anechogenic contents. At ultrasonic scanning of inflamed mammary gland the decrease in echogenicity tissues is noted.

Keywords: mastitis, endometritis, mammary gland, sexual system, inflammatory process, dogs, boughs, females, inflammation of a mammary gland, inflammation of sexual system of a female, endometrium inflammation.

Введение. Матка - вместилище и одновременно «инкубатор» для новой жизни, от ее структурной и фуннкциональной полноценности зависят жизнь и здоровье потомства. Функциональная активность матки всецело зависит не только от количества вырабатываемых эффекторных гормонов, их соотношения, но также и от последовательности их выброса в кровь $[1,2]$. Наряду с этим матка сама подвержена различным эндогенным и экзогенным воздействиям, как механическим (травмы), так и биологическим (бактерии, вирусы, грибы, паразиты). Многофакторность поражения матки, сложная система управления ее функцией приводят к частым нарушениям в этом органе. В структуре заболеваний репродуктивных органов поражения матки занимают первое место, а среди них преобладают эндометриты [3, 4]. Возрастающая актуальность проблемы эндометритов собак связана, наряду с увеличением числа больных животных и высокой летальностью при этой патологии, со значительными экономическими затратами на лечение. Не менее распространенной и важной проблемой является мастит у собак [5]. Здоровье и функциональная способность молочной железы напрямую отражаются не только на общем состоянии животного, но и на жизнеспособности потомства. В связи с этим своевременная дифференциальная диагностика маститов и эндометритов, их действенная профилактика и качественная терапия позволяют сохранить репродукцию племенных породистых собак и обеспечить их квалифицированное разведение [6].

Учитывая сложность патогенеза, стадийность течения, многоликость клинических проявлений эндометритов у собак и связанные с этим большие трудности в постановке правильного диагноза, а следовательно, адекватной терапии, мы поставили цель установить корреляцию заболеваемости маститом и эндометритом у сук.

Для достижения поставленной цели решались следующие задачи: изучить возрастную и породную предрасположенность мастита и эндометрита у собак; клинические признаки при мастите и эндометрите у сук; данные ультразву- 
кового исследования у собак, больных маститом и эндомеритом.

Объекты исследований - собаки различных пород, поступающие в ветеринарную клинику «Черная кошка, белый кот» города Азова Ростовской области. Тщательно изучали сук в возрасте от 1 года до 10 лет. При исследовании обращали внимание на общее состояние животных, состояние молочных желез, а также производили вагинальное и ультразвуковое исследование.

Результаты исследований и их обсуждение. На первом этапе исследований проводили анализ возрастной предрасположенности к заболеваемости маститом и эндометритом у животных. Исследованию подверглось 40 собак с диагнозом мастит и эндометрит.

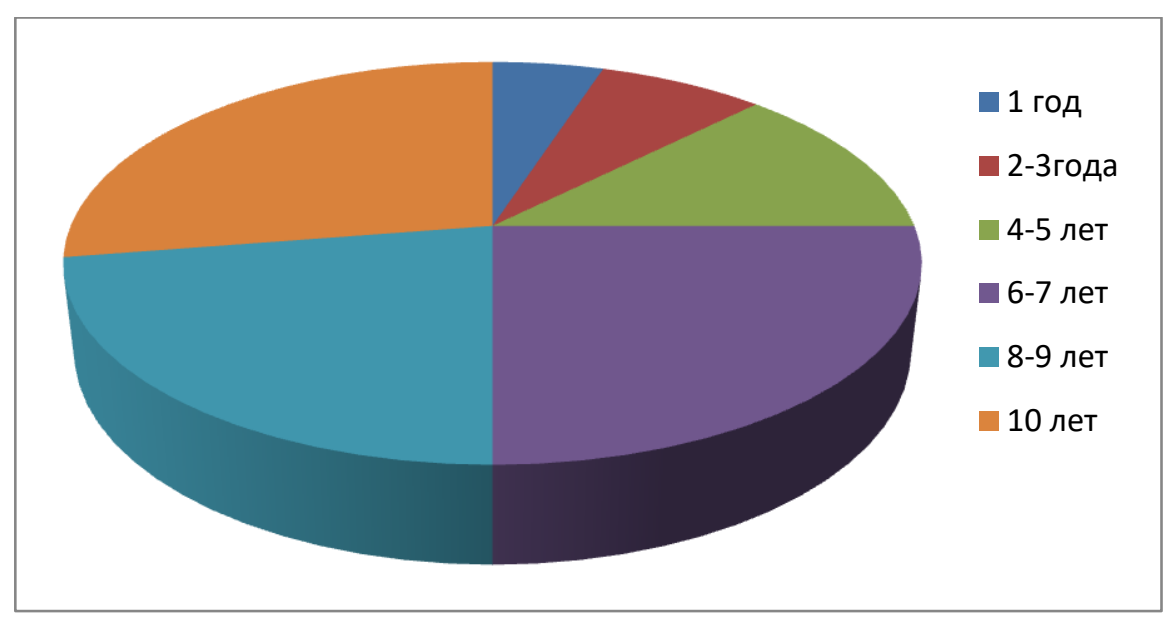

Puс. 1. Возрастная предрасположенность к заболеваемости маститом и эндометритом у собак

В результате исследований установлена взаимосвязь заболеваемости маститом и эндометритом у сук с возрастом. Так, чаще всего болеют животные в возрасте от 6 лет до 10 лет.
Собаки в возрасте одного года заболевают маститом и эндометритом в $5 \%$ случаев; в период с 2 до 3 лет - 7,5; с 4-5 лет - 12,5; с 6-7 лет - 25; с 8-9 лет $-22,5$; с 10 лет $-27,5 \%$.

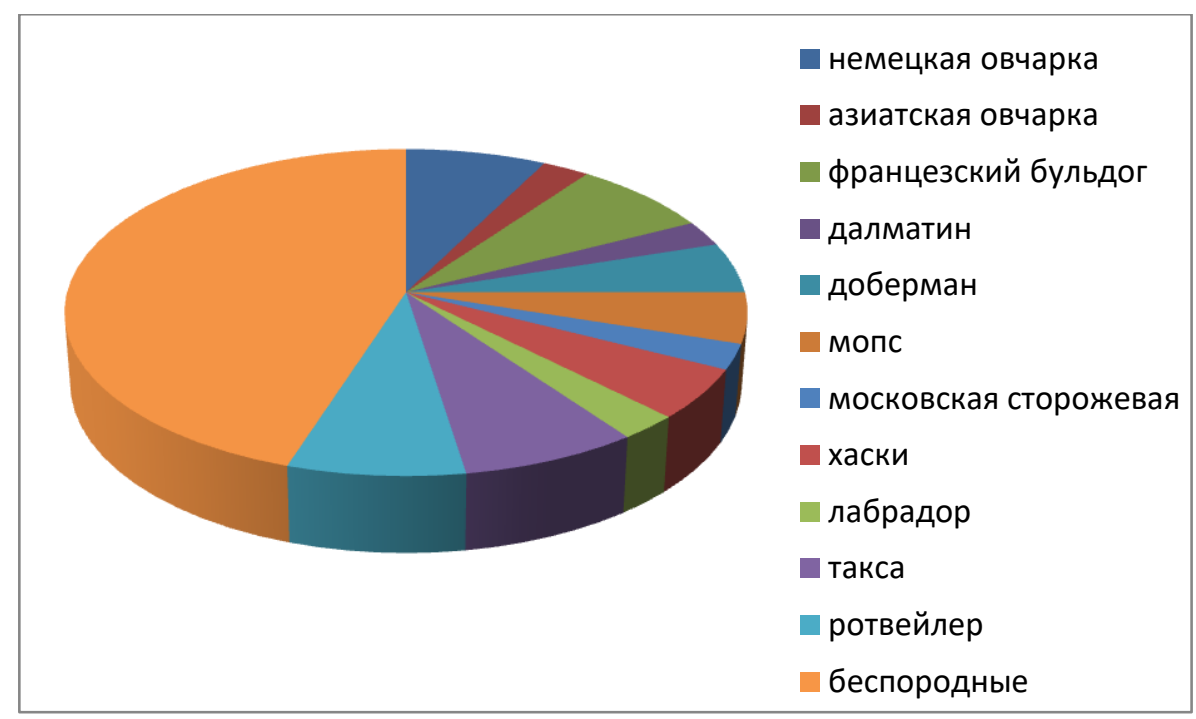

Puc. 2. Породная предрасположенность заболеваемости маститом и эндометритом у собак

При анализе распространенности заболеваний в зависимости от породы собак пришли к выводу, что существенной предрасположенности к этим заболеваниям не выявлено. Однако 
чаще всего на прием попадают беспородные животные. Так, азиатские овчарки, далматины, московские сторожевые и лабрадоры заболевали в 2,5 \% случаев, доберманы, мопсы, хаски в $5 \%$ случаев, немецкие овчарки, французские бульдоги, таксы и ротвейлеры - в 7,5 \% случаев, а в $45 \%$ случаев заболевали беспородные животные.

При эндометрите у сук общее состояние животного чаще всего угнетено, температура тела повышена, отмечается одышка, полидипсия, снижение аппетита или полный отказ от корма. При пальпации брюшная стенка напряжена, болезненная, тело и рога матки увеличены. При вагинальном исследовании слизистая оболочка преддверия и влагалища гиперемирована, отечная, влажная; влагалищная часть шейки матки увеличена, цервикальный канал приоткрыт, отмечается выделение экссудата беложелтого цвета с неприятным запахом.

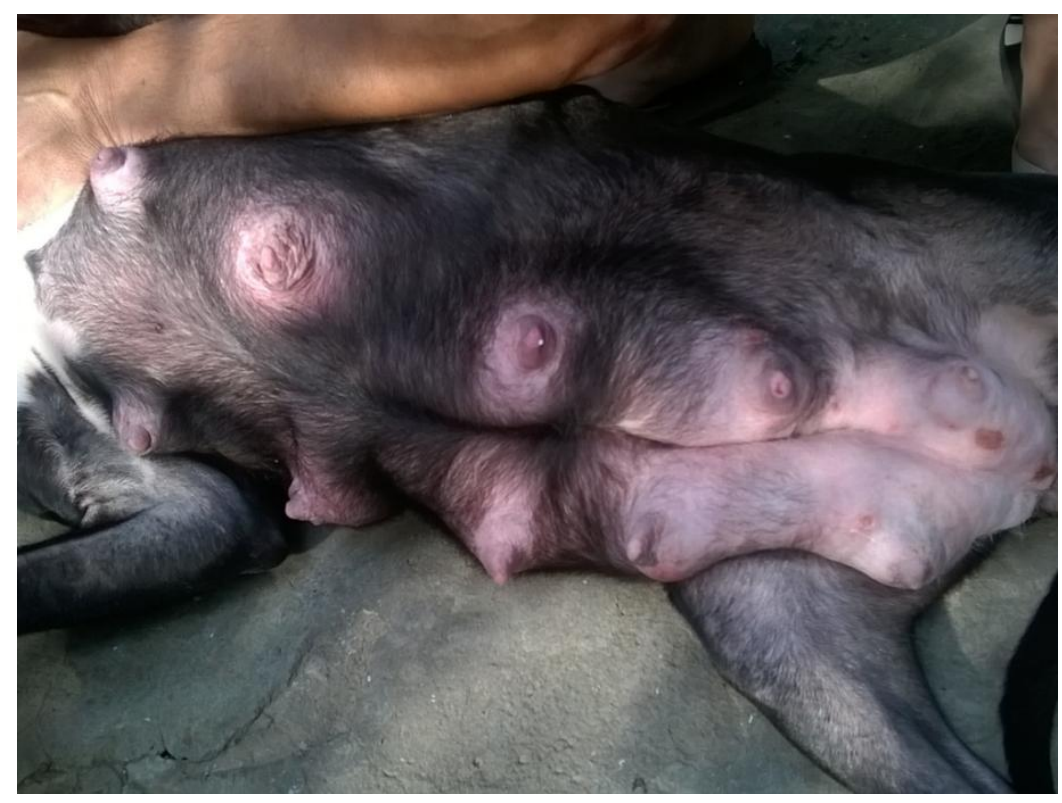

Puc. 3. Молочная железа при мастите у собак

При клиническом обследовании самок, больных маститом, установлено, что патологический процесс локализуется в основном в молочной железе и лишь в некоторых случаях отражается на общем состоянии животного. Молочная железа увеличена в размере, горячая на ощупь, гиперемирована, болезненна, из сосков с трудом выделяется секрет серо-желтого цвета. Общая температура тела у собак находится на верхних границах нормы либо незначительно ее превышает, также отмечается полидипсия.

\section{Исследование корреляции маститов и эндометритов у сук $(\mathrm{n}=40)$}

\begin{tabular}{|c|c|c|c|c|c|c|c|}
\hline \multicolumn{2}{|c|}{$\begin{array}{c}\text { Без патологии } \\
\text { половых органов }\end{array}$} & \multicolumn{2}{c|}{$\begin{array}{c}\text { Послеродовый } \\
\text { эндометрит }\end{array}$} & \multicolumn{2}{c|}{$\begin{array}{c}\text { Задержание } \\
\text { последа }\end{array}$} & \multicolumn{2}{c|}{$\begin{array}{c}\text { Осложненные } \\
\text { роды }\end{array}$} \\
\hline голов & $\%$ & голов & $\%$ & голов & $\%$ & голов & $\%$ \\
\hline 6 & 15 & 29 & 72,5 & 2 & 5 & 3 & 7,5 \\
\hline
\end{tabular}

В таблице отражена корреляция между маститом и эндометритом у самок собак. В ходе исследований установлено, что при заболеваемости маститом у собак одновременно встреча- ется воспаление эндометрия (29\%), осложненные роды предшествуют маститу лишь в 7,5\% случаев, задержание последа - в 5 \%. 


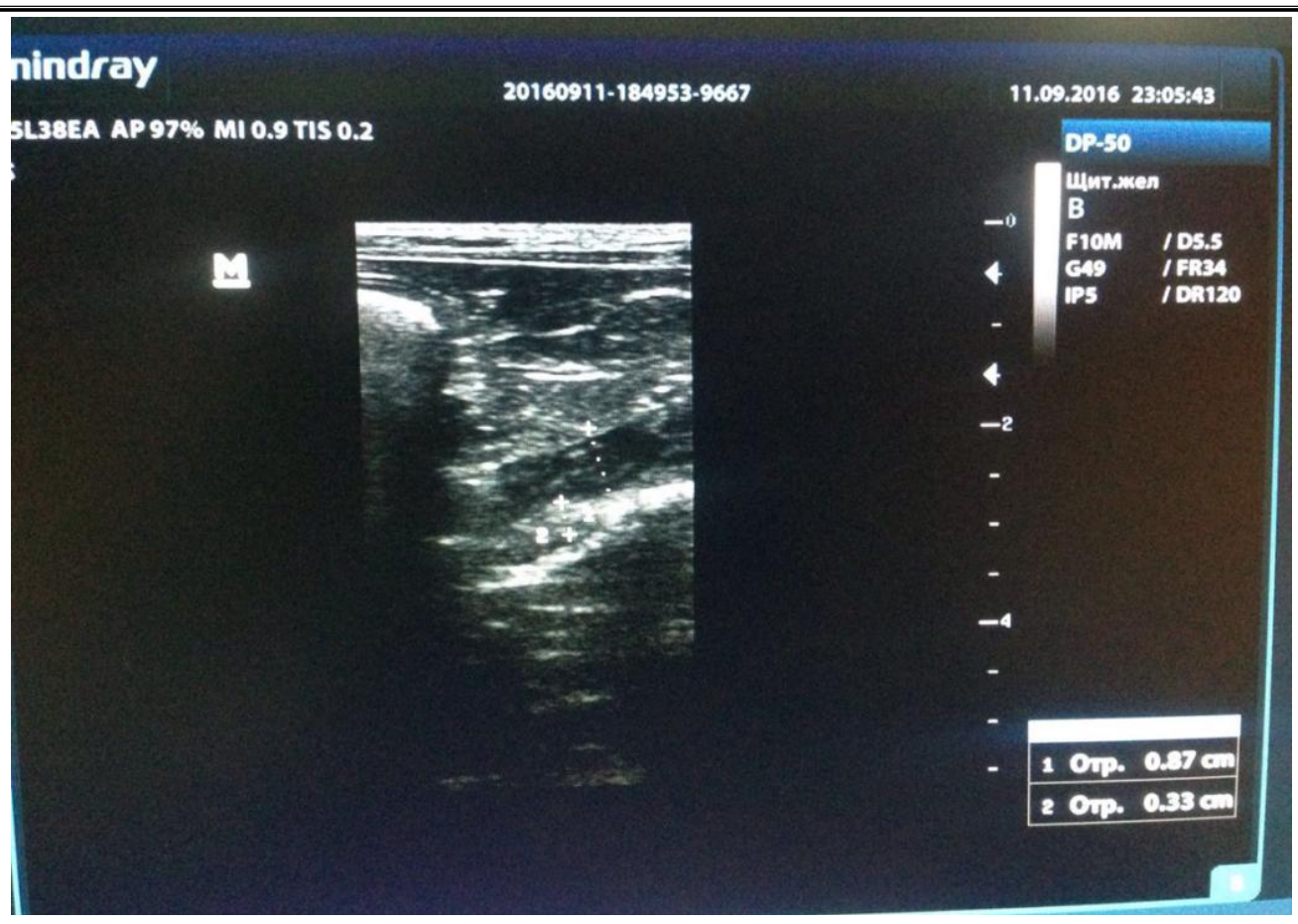

Pис. 4. Ультразвуковое исследование при эндометрите у собаки

При ультразвуковом сканировании установили: матка визуализируется хорошо, стенки утолщены до 3-5 мм, эхогенность снижена, эндометрий утолщен, небольшое количество анэхогенного содержимого, очаговых образований нет. Диаметр рогов матки 9-11 мм, диаметр тела матки - 15 мм.

При ультразвуковом сканировании воспаленной молочной железы отмечается снижение эхогенности тканей.

\section{Выводы}

1. Установлена корреляция заболеваемости маститом и эндометритом с возрастом у сук. Заболеваемость у сук старше 6 лет составляет в среднем $25 \%$.

2. При анализе распространенности заболеваний в зависимости от породы собак пришли к выводу, что существенной породной предрасположенности к этим заболеваниям не выявлено. Однако чаще болеют беспородные животные.

3. При мастите молочная железа увеличена в размере, горячая на ощупь, гиперемирована, болезненна, из сосков с трудом выделяется секрет серо-желтого цвета. Общая температура тела у собак находится на верхних границах нормы либо незначительно её превышает, также отмечается полидипсия.

4. При эндометрите у сук общее состояние животного угнетено, температура тела повышена, отмечается одышка, полидипсия, снижение аппетита или полный отказ от корма. При пальпации брюшная стенка напряжена, болезненная, тело и рога матки увеличены. При вагинальном исследовании слизистая оболочка преддверия и влагалища гиперемирована, отечная, влажная; влагалищная часть шейки матки увеличена, цервикальный канал приоткрыт, отмечается выделение экссудата беложелтого цвета с неприятным запахом.

5. При анализе заболеваемости собак маститом и эндометритом была установлена взаимосвязь. При заболеваемости маститом у собак одновременно встречается воспаление эндометрия (29\%), осложненные роды предшествуют маститу лишь в 7,5 \% случаев, задержание последа - в $5 \%$.

6. При ультразвуковом сканировании матка визуализируется хорошо, стенки утолщены, эхогенность снижена, эндометрий утолщен, небольшое количество анэхогенного содержимого.

7. При ультразвуковом сканировании воспаленной молочной железы отмечается снижение эхогенности тканей. 


\section{Литература}

1. Пензурова С.А., Чекуров И.В. Гистопатология хронических эндометритов у собак // Известия Оренбургского государственного аграрного университета. - 2014. - № 1 (45). C. 86-88.

2. Карташов Е.В., Шафрикова А.В., Ермакова И.А. Некоторые аспекты возникновения хронических эндометритов у собак // Ветеринария Кубани. - 2009. - № 2. - С. 21-23.

3. Диагностика и лечение острого эндометрита у собак и кошек / H.B. Шульгин, C.A. Muхалевская, И.Н. Мягков [и др.] // Наука, образование, общество: актуальные вопросы и перспективы развития: мат-лы Междунар. науч.-практ. конф. - М.: 000 «АРКОНСАЛТ», 2015. - С. 84-85.

4. Войтенко Л.Г., Чекрышева В.В., Облап О.М. Эфффективность нового средства для лечения эндометрита у животных // Актуальные проблемы и методические подходы к диагностике, лечению и профиллактике болезней животных: мат-лы Междунар. науч.-практ. конф. - М., 2018. C. 40-43.

5. Шафикова А.В. Этиология, диагностика и лечение при эндометритах у собак: дис. ... канд. ветеринар. наук: 16.00.07. - пос. Персиановский, 2006. - 152 с.

6. Чекрышева В.В., Гаркуша А.К. Сочетанная патология при эндометрите у собак // Вестник Мичуринского государственного аграрного университета. - 2018. - № 4. C. $153-156$.

\section{Literatura}

1. Penzurova S.A., Chekurov I.V. Gistopatologija hronicheskih jendometritov u sobak // Izvestija Orenburgskogo gosudarstvennogo agrarnogo universiteta. - 2014. - № 1 (45). - S. 86-88.

2. Kartashov E.V., Shafikova A.V., Ermakova I.A. Nekotorye aspekty vozniknovenija hronicheskih jendometritov u sobak // Veterinarija Kubani. 2009. - № 2. - S. 21-23.

3. Diagnostika i lechenie ostrogo jendometrita u sobak i koshek / N.V. Shul'gin, S.A. Mihalevskaja, I.N. Mjagkov [i dr.] // Nauka, obrazovanie, obshhestvo: aktual'nye voprosy i perspektivy razvitija: mat-ly Mezhdunar. nauch.-prakt. konf. - M.: 000 «ARKONSALT», 2015. - S. 84-85.

4. Vojtenko L.G., Chekrysheva V.V., Oblap O.M. Jeffektivnost' novogo sredstva dlja lechenija jendometrita u zhivotnyh // Aktual'nye problemy i metodicheskie podhody $k$ diagnostike, lecheniju i profilaktike boleznej zhivotnyh: mat-ly Mezhdunar. nauch.-prakt. konf. - M., 2018. - S. 40-43.

5. Shafikova A.V. Jetiologija, diagnostika i lechenie pri jendometritah u sobak: dis. ... kand. veterinar. nauk: 16.00.07. - pos. Persianovskij, 2006. - $152 \mathrm{~s}$.

6. Chekrysheva V.V., Garkusha A.K. Sochetannaja patologija pri jendometrite u sobak // Vestnik Michurinskogo gosudarstvennogo agrarnogo universiteta. - 2018. - № 4. S. 153-156. 